the limb could be easily read, and an unanswerable record of the progress of the case kept. Round the rod, moreover, was placed the spiral steel spring of the necessary strength; and it is the efficiency of this arrangement which is remarkable; the force so evoked, although elastic, lacking the extreme resiliency which sometimes is a drawback

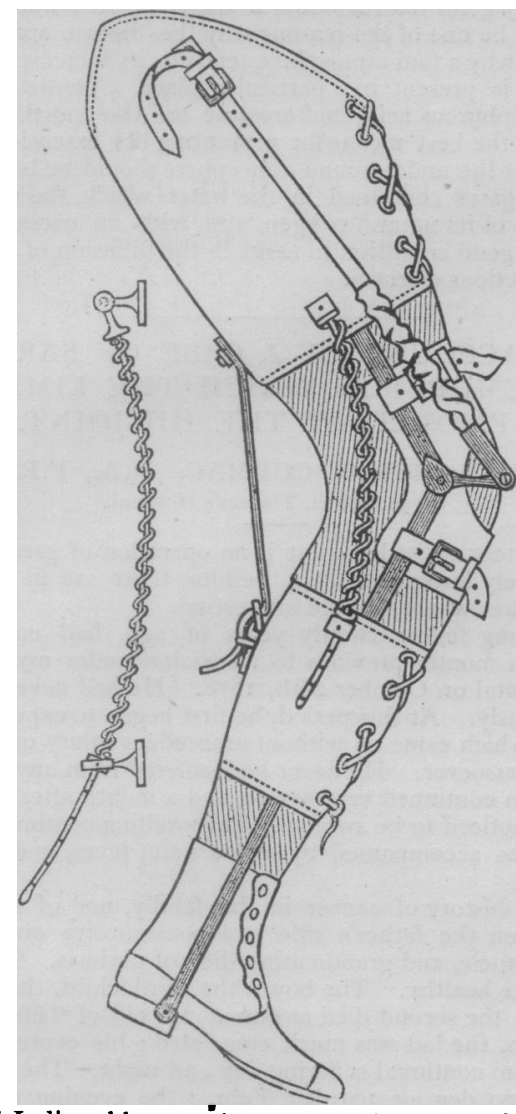

in the use of India-rubber tension. A check-strap at the back of the apparatus controlled the extensor agents, and allowed the instrument to be fixed at any angle suitable for its appliance.

The results attendant on the trial of the mechanism were speedily evident, On November 15th, it was adapted, the graduometer marking 75 deg.; two days later, the angle had diminished to $62 \mathrm{deg}$.; on the day following, to $54 \mathrm{deg}$; and by the $23 \mathrm{rd}$, to $35 \mathrm{deg}$. A week afterwards, 26 deg. only remained from the vertical, increased power having been added to make up the deficiency incurred by the altered position of the limb and consequent mechanical disadvantage of the power at work. The toe first, and ultimately the entire sole of the foot, were brought to the ground; and at the present time the patient is commencing to walk on the debilitated limb.

\section{CASE IN WHICH A TESTICLE CONGENITALLY DISPLACED INTO THE PERINÆUM WAS SUCCESSFULLY TRANSFERRED}

$$
\text { TO THE SCROTUM. }
$$

By THOMAS ANNANDALE, F.R.S.E.,

Professor of Clinical Surgery in the University of Edinburgh.

ON the $15^{\text {th }}$ of June, 1877 , Dr. Irvine of Pitlochry recommended to my care a male child, aged 3, who had been brought to him suffering from pain in the region of the perinæum, which was much aggravated when the little patient was allowed to walk or run. It was noticed that some abnormality existed in connection with the right testicle shortly after birth, but it was only when the child began to walk that the pain directed special attention to the part. Dr. Irvine, finding that the cause of the pain was a displacement of the right testicle, asked me to admit the child into my wards, with the hope that something might be done to relieve the symptoms.

An examination of the patient showed the condition, which is well illustrated in the woodcut, taken from a careful photograph. The right side of the scrotum was empty, but its skin and other tissues were welldeveloped. On searching for the cord, it was felt to come out through

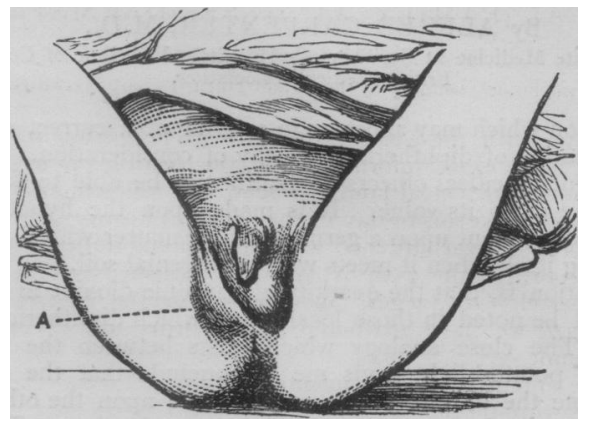

the external abdominal ring in the usual way, but, instead of passing down into the scrotum, it could be traced to the perinæum, where the right testiclelay (A). This displaced testicle was felt to be well-developed, was of the usual size, and was lying under the skin and cellular tissue at a point a little to the right side of the middle line of the perinæum. It was situated at a little lower level than if it had occupied its usual place in the scrotum. When pressure was made over the testicle, it caused much pain. The left testicle was normal in situation and development.

On the 5th of July, I performed the following operation, with a view of transferring the displaced testicle to its proper position in the scrotum. An incision, commencing over the external abdominal ring and extending half way down the scrotum, was made on the right side, so as to expose the cord, which was then seized, and by means of it the testicle was drawn out from its abnormal position. This was not done without the division of some adhesions, and there was one fibrous band attached to the bottom of the testicle above and to the tuberosity of the ischium below, which appeared to correspond to one process of the gubernaculum testis, and which required to be cut across before the testicle would leave the perinzum. The scrotum was now opened up more freely, and the drawn-out testicle was placed in it and securely fixed there by means of a catgut stitch passed through the bottom of the scrotum and lower part of the testicle. The opening into the perinæum along which the cord and testicle had passed was subcutaneously stitched with catgut, and a small counter-opening made at the most dependent point of the perineal cavity which had contained the testicle, so as to allow any fluid to drain away and insure the complete closure of the cavity and prevent the testicle from passing again into it. The wound in the scrotum and groin having been stitched, antiseptic dressing was applied. The whole of the operation was performed antiseptically.

The patient's progress after the operation was satisfactory in every way, and the wounds were healed on the 3 Ist of July. A few days afterwards, he returned home with his testicle securely resting in the scrotum in a perfectly natural manner.

In November of the same year, Dr. Robert Irvine was kind enough to write me that he had recently examined the boy, and had found both testicles in the scrotum, and occupying much the same position on their respective sides; the only difference between the two being that the right one felt a little smaller and harder, was more deeply situated, and somewhat more fixed than the left one.

REMARKs.-I record the case, first because it is an illustrative example of a rare congenital affection of the testicle ; and, secondly, because, as far as I can ascertain, it is the first instance in which a testicle so displaced has been successfully transferred to and permanently retained in the scrotum.

Mr. Curling, in his very valuable work On Diseases of the Testis, relates a case very similar to the one just reported,-in which he endeavoured to replace and retain the testicle in the scrotum, but he did not succeed in doing so, owing, he thinks, to "the cremaster retracting the organ after the separation of the adhesions which retained it, as the cord was quite long enough to admit of its removal to the intended site". Mr. Curling further remarks : "In another operation, I should endeavour to secure the testicle to the bottom of the scrotum with a suture." The employment of the subcutaneous catgut suture so as to close completely the perineal cavity, in addition to stitching the testicle to the bottom of the scrotum, as suggested by Mr. Curling, insured, I consider, the success of my operation; and I would, therefore, advocate this proceeding in every similar case. 